\title{
CORRESPONDENCE
}

\section{MEDICAL TREATMENT OF CATARACT}

To the Editor of The British Journal of Ophthalmology

SIR,--Since reporting my cases of spontaneous absorption of cataract I have observed one more. Mr. G. Victor Miller's very interesting confirmatory cases will help much in showing up the truth. I think we are able now to put my theory on to a firmer basis : that degeneration and regeneration are at work. At the extremely interesting slit-lamp course at Oxford at Christmas I had the privilege of learning from Mr. Harrison Butler's lucid lectures and lantern slide projections of his pictures drawn from actual cases, as from Dr. Franceschetti's direct messages of Prof. Vogt's investigations, that one form of degeneration and restitution can actually be studied with the slit-lamp. I refer to those cases, where certain lacunae or fluid-gaps form in the cortex near the capsule, and are seen to disappear. Such pathological processes, taking place within the area of the pupil, would affect vision for the worse. Then closing up, it would improve. We must not say that, because medical treatment so far is very unconvincing, it can never be otherwise. It is conceivable that therapeutic remedies will be found whose efficacy in promoting restitution will prove to be above suspicion.

Yours faithfully,

GeORGE Young.

Colchester.

January 15, 1925.

\section{OBITUARY NOTICE}

SIR ANDERSON CRITCHETT, BART., K.C.V.O., F.R.C.S.E. Surgeon-Oculist to the King.

The death of Sir Anderson Critchett on Monday, February 9, removes from the ranks of British ophthalmologists one of its best known and best loved figures. For years he has been looked up to and respected as the doyen of eye surgeons, and he has filled with distinction every post of honour which his colleagues could confer on him. For close on a century the name of Critchett has been associated with ophthalmic surgery. His father, George 


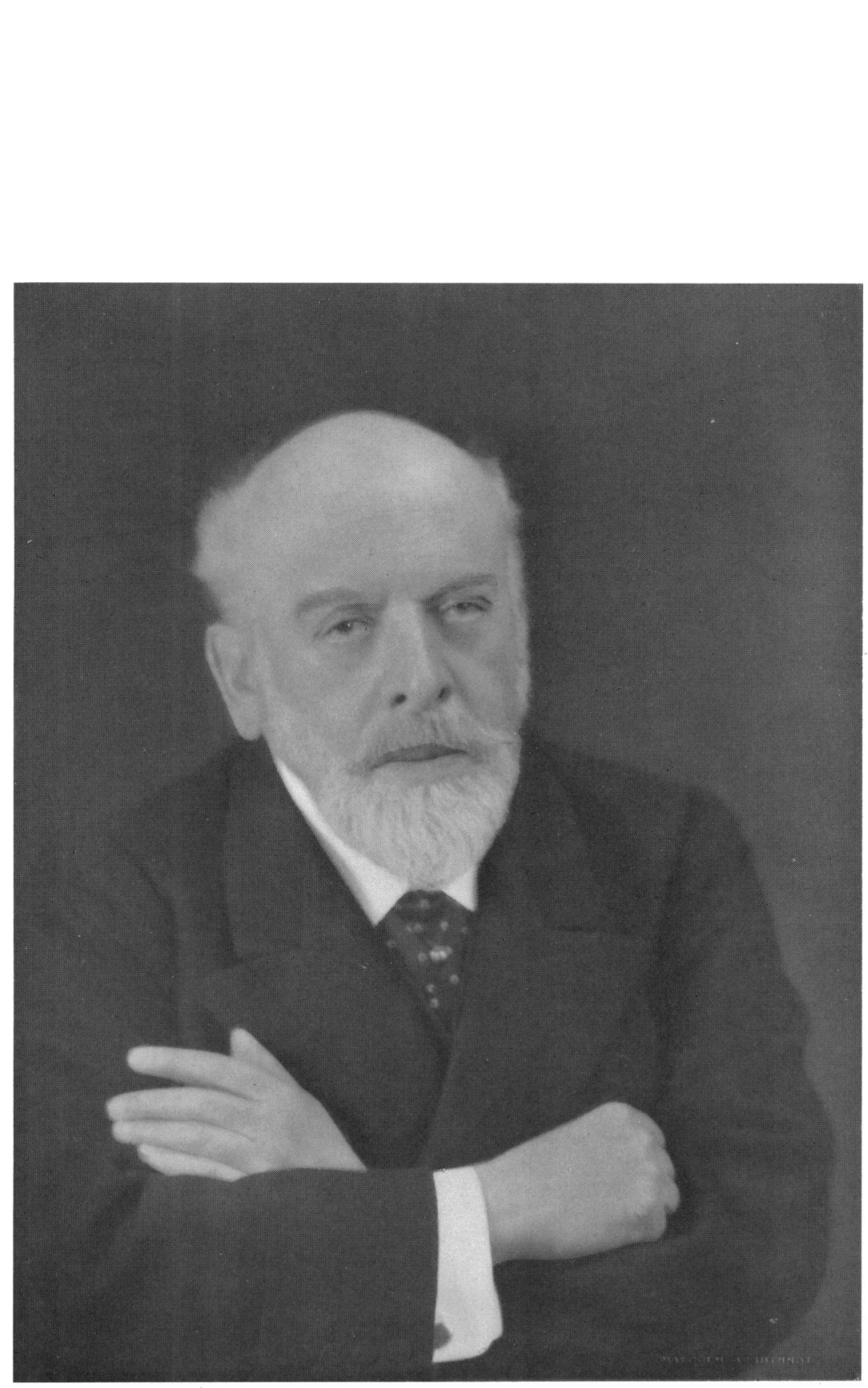

$\overrightarrow{0}$

$\overrightarrow{\vec{\omega}}$

ต

흥.

6

$\omega$

$\vec{a}$

SIR ANDERSON CRITCHETT, BART., K.C.V.O., F.R.C.S.E. SURgeoy-OCulist to the king. 
Critchett, qualified in 1839 and was one of the founders of modern ophthalmology in England. Bowman, Hutchinson, Lawson and Critchett were the great names in the ophthalmic world in the middle of last century, and George Anderson Critchett, the eldest son of the last-named, born in 1845, was approaching manhood when the discovery of the ophthalmoscope opened up a new era in the study of diseases of the eye. His father achieved a great reputation in his day, and it is not always an easy matter for a son to follow in his father's footsteps, but, in the case of Anderson Critchett, it is safe to say that he added lustre to a name that his father had already made famous.

$\mathrm{He}$ received his early education at Harrow. and retained to the end the greatest love for and pride in his old school. The cheers with which he was greeted when he went to Harrow on Speech Day in the summer of 1908 , after he had been made a Baronet, gave him more happiness than aimost any other recognition of that honour. At Harrow, he won the prize for English Literature and though he did not actually gain a place in the eleven, he laid the foundations of a good cricketing style which served him well when, later on, he went up to Caius College, Cambridge. At Caius, he captained the cricket eleven, and made many friends. $\mathrm{He}$ graduated in 1867 and immediately after began to study medicine at the Middlesex Hospital and qualified in 1872. There followed a period in his career when it seemed almost doubtful whether medicine or music should claim him. He possessed a fine baritone voice and a love for the drama and social qualities which all acted together to draw him away from the serious profession of medicine. His affection for his father and his desire to be of assistance to him proved an effective counterbalance to these attractions and from that time onwards he seriously ${ }^{*}$ devoted himself to the study of ophthalmology. He speedily began to acquire a wide reputation and it is of interest to note that his first published paper on "Inoculation in Ophthalmic Practice" was published in a French journal Annales d'Oculistique in 1877.

In 1879 he became ophthalmic surgeon to the Royal Free Hospital and in 1881 he was elected out of a strong field of candidates ophthalmic surgeon to St. Mary's Hospital, and it was his work there that finally established his reputation and incidentally built up one of the biggest eye clinics at any of the general hospitals in London. Critchett himself would be the first to recognize how much he was aided in his work at St. Mary's by the late Henry Juler and how loyally they worked together when, a few years later, Juler was co-opted as his colleague.

His career from now onwards is a simple record of increasing honours accorded to him. In 1889 he was elected President of the 
Ophthalmic Section of the British Medical Association. In 1894, at Edinburgh and again in 1899, at Utrecht, he was elected an honorary President of the International Ophthalmological Congress. From 1899 to 1901 he was President of the Ophthalmological Society of the United Kingdom. He became SurgeonOculist to King Edward VII in 1901, and was knighted in the same year. In 1905, King Edward created him a Commander of the Victorian Order, and in 1908, he was raised to the rank of Baronet. In 1912, when a new section of ophthalmology was started in the Royal Society of Medicine, he was the first President. In 1913, he was President of the Section of Ophthalmology of the International Medical Congress at London and in 1918, on the foundation of the new Council of British Ophthalmologists, he was elected the first President of that body. In 1919, in recognition of his war services to King George the Fifth Hospital, he was made a Knight of Grace of the Order of St. John of Jerusalem, and in the same year was created a K.C.V.O. Last year, 1924, he was elected Master of the Oxford Ophthalmological Congress, of which body he had previously been Honorary Treasurer. Such a record by itself must show the esteem in which Sir Anderson Critchett was held by those who knew him best, an esteem which could only be earned by the genuineness of character which gave rise to it.

He was never a prolific writer, to the regret of many of his pupils, and much of his teaching which would have been of great value is lost for want of recording; but he was a great clinician and unrivalled as an operator. To see Critchett removing a cataract in the heyday of his skill was to see the perfection of operative technique. Never a hurried or purposeless movement was matle and if any untoward complication had to be met, it was faced with the same steady placidity as if it had been foreseen from the first. To the very end of his life he retained this dexterity and within a few weeks of his death he was still operating as skilfully as ever.

An old friend and colleague, writing in The Times of February 10, says of him: "His other great claim to remembrance is the affection and regard which he inspired universally with patients and colleagues. His kindness to his junior colleagues was proverbial. His loyalty to those who brought him patients in consultation enabled them to do their best for their clients. This sincerity and uprightness of character gained for him the affection of patients of all classes." He had to a very high degree the capacity of rousing in his patients a feeling of complete confidence and the equally valuable capacity of creating a feeling of friendship in his colleagues. Apart from his work, probably this was 
his most characteristic trait; an essential friendliness of spirit arising from a genuine and unselfish interest in the other man. It is little wonder that he had such a wide circle of friends, and that his presence was welcomed in so many different spheres. He had a ready wit and a happy art of turning a phrase, and even a delight in an old-fashioned paronomasia. He was never afraid to make a pun after dinner or when suddenly called on for any complimentary speech, but he always, as he himself said not very long ago, remembered that his duty in proposing the health of a guest was "to toast him, not to butter him." He was at his best when the party was not too large and when there was someone nearly contemporary present to help to prompt his memory of old days and ways. As he said of himself, he was a "clubbable" man.

To few men has it been given to have such a happy and such a full life; happy in his work, happy in his friendships and happy beyond expression in his family life, he reached the end of his long term of years without ever growing old.

\section{NOTES}

DR. E. K. RoY-THOMAS has been appointed
Appointment the Swansea General and Eye Hospital.

Visual Tests in the Air Services

OpнтнALmic Surgeons who are interested in the tests of vision employed in the Air Services will find these fully detailed in the Lancet for November 29, 1924, by Dr. Kenneth R. Smith, late of the R.A.F. Medical Service.

British Medical Association

THE Ninety-third Annual Meeting of the British Medical Association will be held at Bath, from July 21 to 24,1925 . The officers of the Ophthalmic Section are as follows :-President : W. Mardon Beaumont. (Bath). Vice-Presidents: R. Wallace Henry, M.D. (Leicester) ; A. W. Ormond, C.B.E. (London) ; C. H. Walker (Bristol). Honorary Secretaries : R. Colley, M.B., D.O.M.S., 30, The Circus, Bath ; P. G. Doyne, M.B., 8, Harley St., London, W.1. 